\title{
A mechanical heart valve is the best choice
}

\author{
Iqbal H Jaffer, ${ }^{1,2}$ Richard P Whitlock ${ }^{2,3}$
}

\begin{abstract}
${ }^{1}$ Thrombosis and
Atherosclerosis Research

Institute, McMaster University, Hamilton, Ontario, Canada

${ }^{2}$ Division of Cardiac Surgery, McMaster University, Hamilton, Ontario, Canada

${ }^{3}$ Population Health Research Institute, McMaster University, Hamilton, Ontario, Canada
\end{abstract}

\section{Correspondence to}

Dr Richard P Whitlock,

Population Health Research Institute, McMaster University, DBCVSRI, Room 1C1-5B, 237 Barton Street East, Hamilton, Ontario, Canada L8L 2X2; richard.whitlock@phri.ca

Received 9 February 2016 Accepted 10 February 2016

\section{SLinked}

- http://dx.doi.org/10.1136/ heartasia-2015-010650

\section{CrossMark}

To cite: Jaffer $\mathrm{IH}$, Whitlock RP. Heart Asia 2016;8:62-64.

doi:10.1136/heartasia-2015010660

\section{ABSTRACT}

The choice of prosthesis type in patients with valvular heart disease should always be individualised. The treating heart team must weigh the concerns surrounding durability of bioprosthetic valves compared with mechanical valves and the need for lifelong anticoagulation required with mechanical valves. In general, guidelines recommend that patients under the age of 60 would benefit from a mechanical valve, and those over 70 would benefit from a bioprosthetic valve. We would argue, in this context, that the most appropriate choice for this patient would be undertaking a mitral valve replacement with a mechanical prosthesis. This recommendation is based on two considerations: first, there is a high likelihood of failure of a bioprosthesis within an unacceptably short period of time, which would then necessitate a higher risk reoperation. Second, there is high likelihood of needing long-term anticoagulation in a patient with severe mitral stenosis due to the development of atrial fibrillation. While we do acknowledge the difficulty in managing long-term anticoagulation of patients in rural settings, there have nonetheless been significant advancements in this realm with the use of pharmacist-led thrombosis clinics and point of care international normalised ratio (INR) devices in the treatment of rural patients in lowincome and middle-income countries. For these reasons, therefore, we would strongly advocate for a mechanical valve in this 44-year-old patient from a rural setting.

\section{INTRODUCTION}

Patients younger than 60 years of age must carefully choose their valve prosthesis given the implications that the choices entail. Whereas bioprosthetic valves unburden patients from the need for lifelong anticoagulation, they are prone to structural valve degeneration, which increases the likelihood of reoperation and its associated risks. ${ }^{1}{ }^{2}$ Structural failure occurs more rapidly in those patients who are younger, especially when those valves are placed on the left side of the heart. ${ }^{1}$ Conversely, those who choose a mechanical valve avoid the risk of structural valve degeneration at the cost of lifelong anticoagulation. It is this second issue of anticoagulation that carries greatest weight in prosthesis choice in many patients, especially those engaged in professions or activities that increase the probability of haemorrhagic complications. The case study presented herein details the case of a 44-year-old man from a rural setting who presents with progressive dyspnoea and is found to have severe mitral stenosis, with moderate pulmonary hypertension, and is requiring mitral valve replacement (MVR). In this type of patient, we would advocate for MVR with a mechanical heart valve for two reasons. First, there is a high likelihood of requiring reoperation with a bioprosthetic valve in an unacceptably short duration of time, resulting in an increased risk for reoperation. Second, the clinical characteristics of such a patient result in a high lifetime likelihood of requiring long-term anticoagulation due to the high potential of developing atrial fibrillation (AF).

\section{BIOPROSTHETIC VALVES: YOUNGER PATIENTS SHOULD APPROACH WITH CAUTION}

Bioprosthetic valves come with several advantages - they are widely available, they are well tolerated, their durability in the elderly is excellent, contemporary preservation methods have extended their lifetime to upwards of 15 years, ${ }^{3}$ and they allow for future implantation of transcatheter-based valve technologies. ${ }^{4} 5$ Despite all of these advantages, it is well understood that bioprosthetic valves have a high failure rate in those patients under the age of 60 , that often necessitates the need for reoperation. ${ }^{6}$ What is not as well understood is the utility of bioprosthetic valves in patients under the age of 50 as is the patient in our scenario. There are reports of bioprosthetic valves used in children and young adults under the age of 30 , and those further reinforce the need for caution in considering bioprosthetic valves in these younger patients. ${ }^{7}$ In that series, bioprosthetic valves-specifically, the Mitroflow LXA-were shown to rapidly calcify, leading to premature valve degeneration and resulting in a progression of none or mild aortic stenosis to severe within 6 months. The freedom from valve failure at 3 years is $18 \%{ }^{7}$

Conversely, mechanical heart valves offer several advantages of their own-they are free from structural valve degeneration, they offer better effective orifice area for a similar sized valve when compared with a bioprosthetic valve, they offer a lower profile making them easier to implant in patients with smaller hearts, and they have demonstrated durability in a wide range of patients. The need for lifelong anticoagulation, which is usually presented as a counterpoint to the choice of a mechanical heart valve, will be discussed below. For now, we will concentrate on the comparisons between bioprosthetic and mechanical heart valves.

All major guidelines have recommended mechanical heart valves in patients under the age of 60 requiring MVR. ${ }^{8}{ }^{9}$ While most of these guidelines base their recommendation on expert opinion (class $\mathrm{C}$ evidence), there are several small studies that support these recommendations. Kaneko et al demonstrated that the implantation of a bioprosthetic valve in the mitral position is a significant predictor of long-term mortality in patients under the age of 65 when compared with a mechanical valve with a hazard of 1.476 (95\% CI 1.073 to 2.031, $\mathrm{p}=0.017) .{ }^{10}$ More importantly, they note that the bleeding risk between the two groups was 
similar, further minimising the argument that mechanical valves and their associated anticoagulation add a significant bleeding risk. ${ }^{10}$ Furthermore, both Ruel et al and Jamieson et al report that the freedom from valve degeneration and reoperation in patients receiving a mechanical MVR compared with bioprosthetic MVR is significantly higher. ${ }^{11} 12$ The 15 -year results of the Veterans Affairs randomised trial also support the contention that for patients $<65$ years old, in the mitral position, a mechanical valve accorded a durability benefit. ${ }^{13}$ In that study, 575 patients who required isolated aortic valve replacement (AVR) or MVR were randomised to receive either a bioprosthetic or mechanical valve. They noted that while mortality and valve-related complications were similar in those patients receiving an MVR, there was a significant benefit conferred on those patients receiving a mechanical valve due primarily to freedom from valve degeneration. ${ }^{13}$ These studies highlight that structural valve degeneration does necessitate the need for reoperation, but the time prior to valve failure is plagued with symptomatic dyspnoea, increasing valve gradients, increased cardiac workload and the potential for the development of heart failure. These features, in addition to the increased age of the patient at reoperation, all factor into the Society of Thoracic Surgeons (STS) calculator database, which predicts elevated risk of surgical mortality. In the current case scenario, assuming all other clinical scenarios remain the same, according to the STS calculator, the risk of morbidity or mortality more than doubles for a mitral valve re-replacement even within 10 years from approximately $5 \%$ for the index operation to $>12 \%$ for the first reoperation. ${ }^{14}$ While many groups have reported acceptable risk with reoperation in patients with a primary bioprosthetic valve, we would argue that a $12 \%$ risk is the more objective risk calculation based on a large cohort of reporting centres that minimises the potential for selection bias within case series and reports. This conservative risk estimate of $12 \%$ does not account for the potential financial burden to the patient, nor the expected convalescence of a second operation that may impact his ability to work, nor any of the underlying social challenges of managing this patient's follow-up care in rural India. In summary, when considering that bioprosthetic valve failure is significant in patients under the age of 60 , the risk of reoperation confers an increased risk to the patient and the social challenges of managing his outpatient care, we would recommend a mechanical heart valve to this patient.

\section{ALLEVIATING THE BURDEN OF ANTICOAGULATION}

The need for lifelong anticoagulation with mechanical heart valves has been well described. ${ }^{15}$ The consequences of ineffective anticoagulation are valve failure from thrombus or pannus formation, thrombosis resulting in distal vessel occlusion and death. ${ }^{16}$ Anticoagulation has always been considered a burden of mechanical heart valves; however, we would propose that in a subset of patients, the benefits of anticoagulation extend beyond being treated for the valve. It is well reported that patients with mitral stenosis have enlarged left atria and the correlation of an enlarged left atrial size to the development of at least one episode of $\mathrm{AF}$ is reported to be between $45 \%$ and $75 \% .{ }^{17}$ Furthermore, moderate pulmonary hypertension also increases the risk of development of $\mathrm{AF}$ and thus, this patient will likely develop a second indication for long-term anticoagulation in the future. ${ }^{18}$ One may argue that this patient may be best treated with a non-vitamin $\mathrm{K}$ antagonist oral anticoagulant (NOAC) in the setting of AF, and the presence of mechanical heart valve would cause this option to be precluded. However, NOACs are currently only approved for the management of non-valvular AF and their safety in patients with any sort of prosthetic valve has not been established. Moreover, the cost of NOAC therapy in this patient may prove to be prohibitive, thus necessitating anticoagulation with a more cost-effective alternative such as a vitamin $\mathrm{K}$ antagonist (VKA).

The management of this patient on a VKA requires ongoing monitoring of the international normalised ratio (INR). One could argue that this monitoring is problematic in such a patient. However, monitoring practices have been established within such jurisdictions before. ${ }^{19}{ }^{20}$ Hodge et al describe the development of a comprehensive INR management programme based in community hospitals and general practitioner clinics in rural Australia. ${ }^{19}$ Using education, protocols and point-of-care INR devices, they report a time in therapeutic range (TTR) of $69 \%$ using the standard INR range of $2.0-3.0$ and $81 \%$ using a slightly expanded range of $1.8-3.0 .{ }^{19}$ They further describe that with the adoption of testing every 14 days, the TTR was as high as $78 \%$, a result that rivals even the best-conducted clinical trials of warfarin. ${ }^{19}{ }^{21}$ Again, it may be argued that Australia is a developed nation and a similar outcome would be harder to achieve in a low/middle-income nation due to a lack of resources. However, Manji et al report similar success in an anticoagulation clinic in rural Kenya. ${ }^{20}$ In this study, they developed a pharmacist-led anticoagulation clinic using point-of-care devices based from a clinic in Eldoret, Kenya. They noted that with education and regular follow-up, the mean TTR was $64.6 \%$ in all-comers, but in the group with mechanical heart valves, the mean TTR was $77 \% .{ }^{20}$ Though the mean TTR for all-comers is numerically lower than the TTR achieved in the Australian clinic, it is again comparable to a TTR achieved in well-conducted clinical trials of warfarin. ${ }^{21}$ Importantly, the subset of patients with a mechanical heart valve achieved similar outcomes to the Australian group, ${ }^{20}$ thereby suggesting that a rural setting and living in a developed nation do not necessarily disadvantage or advantage patients in the management of outpatient anticoagulation. In summary, the likelihood for anticoagulation in this patient, the need for a cost-effective solution, and the management of monitoring of a VKA have all been described as achievable within this patient's context, and therefore, we would contend that this strengthens our position in arguing for a mechanical heart valve.

\section{CONCLUSIONS}

Young patients will continue to present with the need for valve replacement, and until technology advances to the point where valves do not need to be anticoagulated, nor do they fail, the dilemma of these choices will persist. We have argued that in the context of a 44-year-old man from a rural setting, requiring valve replacement for rheumatic mitral stenosis, that the optimal prosthesis is a mechanical heart valve. The freedom from structural valve degeneration, the avoidance of higher risk reoperation, the likelihood of the development of $\mathrm{AF}$ requiring anticoagulation, and the feasibility of managing VKA therapy in his context have served as major reasons why we see but only one choice for this patient: a mechanical heart valve.

Twitter Follow lqbal Jaffer at @ihjaffer and Richard Whitlock at @RichardWhitloc2 Contributors Both $\mathrm{IHJ}$ and RPW contributed to the development and writing of this article.

Competing interests IHJ discloses research support from Boehringer Ingelheim, CCS-Bayer Cardiovascular Trainee Award, and in-kind research support from Sorin Group Canada. RPW discloses financial honoraria from Armetheon and Atricure.

Provenance and peer review Commissioned; internally peer reviewed. 


\section{REFERENCES}

1 Ruel M, Kulik A, Rubens FD, et al. Late incidence and determinants of reoperation in patients with prosthetic heart valves. Eur J Cardiothorac Surg 2004;25:364-70.

2 Johnston DR, Soltesz EG, Vakil N, et al. Long-term durability of bioprosthetic aortic valves: implications from 12,569 implants. Ann Thorac Surg 2015;99:1239-47.

3 Bourguignon T, Bouquiaux-Stablo AL, Loardi C, et al. Very late outcomes for mitral valve replacement with the Carpentier-Edwards pericardial bioprosthesis: 25-year follow-up of 450 implantations. J Thorac Cardiovasc Surg 2014;148:2004-11.e1.

4 Noorani A, Radia R, Bapat V. Challenges in valve-in-valve therapy. J Thorac Dis 2015:7:1501-8.

5 Hamm CW, Arsalan M, Mack MJ. The future of transcatheter aortic valve implantation. Eur Heart J Published Online First: 17 Nov 2015. doi:10.1093/ eurheartj/ehv574

6 Weber A, Noureddine $H$, Englberger L, et al. Ten-year comparison of pericardial tissue valves versus mechanical prostheses for aortic valve replacement in patients younger than 60 years of age. J Thorac Cardiovasc Surg 2012;144:1075-83.

7 Saleeb SF, Newburger JW, Geva T, et al. Accelerated degeneration of a bovine pericardial bioprosthetic aortic valve in children and young adults. Circulation 2014;130:51-60.

8 Nishimura RA, Otto CM, Bonow RO, et al. 2014 AHA/ACC guideline for the management of patients with valvular heart disease: a report of the American College of Cardiology/American Heart Association Task Force on Practice Guidelines. J Thorac Cardiovasc Surg 2014;148:e1-132.

9 Vahanian A, Alfieri O, Andreotti F, et al. Guidelines on the management of valvular heart disease (version 2012): the Joint Task Force on the Management of Valvular Heart Disease of the European Society of Cardiology (ESC) and the European Association for Cardio-Thoracic Surgery (EACTS). Eur J Cardiothorac Surg 2012;42: S1-44.

10 Kaneko T, Aranki S, Javed Q, et al. Mechanical versus bioprosthetic mitral valve replacement in patients $<65$ years old. J Thorac Cardiovasc Surg 2014;147:117-26.
11 Ruel M, Chan V, Bédard $\mathrm{P}$, et al. Very long-term survival implications of heart valve replacement with tissue versus mechanical prostheses in adults $<60$ years of age. Circulation 2007;116(11 Suppl):1294-300.

12 Jamieson WR, von Lipinski O, Miyagishima RT, et al. Performance of bioprostheses and mechanical prostheses assessed by composites of valve-related complications to 15 years after mitral valve replacement. J Thorac Cardiovasc Surg 2005; 129:1301-8.

13 Hammermeister K, Sethi GK, Henderson WG, et al. Outcomes 15 years after valve replacement with a mechanical versus a bioprosthetic valve: final report of the Veterans Affairs randomized trial. J Am Coll Cardiol 2000;36:1152-8.

14 Surgeons SoT. STS Risk Calculator. http://riskcalc.sts.org/stswebriskcalc/-/calculate

15 Kulik A, Rubens FD, Wells PS, et al. Early postoperative anticoagulation after mechanical valve replacement: a systematic review. Ann Thorac Surg 2006;81:770-81.

16 Cannegieter SC, Rosendaal FR, Briet E. Thromboembolic and bleeding complications in patients with mechanical heart valve prostheses. Circulation 1994;89:635-41.

17 Probst $\mathrm{P}$, Goldschlager N, Selzer A. Left atrial size and atrial fibrillation in mitral stenosis. Factors influencing their relationship. Circulation 1973;48:1282-7.

18 Miyata-Fukuoka $Y$, Izumo M, Shimada $Y$, et al. Left atrial size and function are related to pulmonary hypertension in coronary artery disease. Echocardiography 2012;29:535-40.

19 Hodge $\mathrm{K}$, Janus $\mathrm{E}$, Sundararajan $\mathrm{V}$, et al. Coordinated anticoagulation management in a rural setting. Aust Fam Physician 2008;37:280-3.

20 Manji I, Pastakia SD, Do AN, et al. Performance outcomes of a pharmacist-managed anticoagulation clinic in the rural, resource-constrained setting of Eldoret, Kenya. J Thromb Haemost 2011;9:2215-20.

21 Tajer C, Ceresetto J, Bottaro FJ, et al. Assessment of the quality of chronic anticoagulation control with time in therapeutic range in atrial fibrillation patients treated with vitamin $\mathrm{K}$ antagonists by hemostasis specialists: the TERRA Registry: Tiempo en rango en la Republica Argentina. Clin Appl Thromb Hemost Published Online First: 5 Jan 2016. doi:10.1177/1076029615623378 